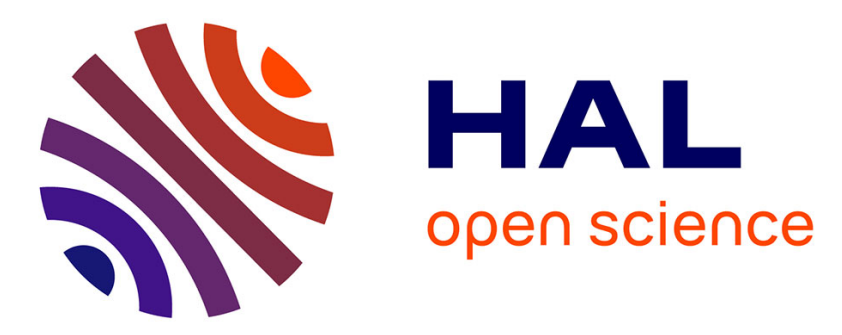

\title{
Is a universal model to describe liquid/liquid extraction of cations by use of ionic liquids at reach?
}

\author{
Isabelle Billard, Ali Ouadi, Clotilde Gaillard
}

\section{To cite this version:}

Isabelle Billard, Ali Ouadi, Clotilde Gaillard. Is a universal model to describe liquid/liquid extraction of cations by use of ionic liquids at reach?. Dalton Transactions, 2013, 42 (17), pp.6203-6212. 10.1039/C3DT32159B . hal-02271584

\section{HAL Id: hal-02271584 \\ https://hal.science/hal-02271584}

Submitted on 27 Aug 2019

HAL is a multi-disciplinary open access archive for the deposit and dissemination of scientific research documents, whether they are published or not. The documents may come from teaching and research institutions in France or abroad, or from public or private research centers.
L'archive ouverte pluridisciplinaire HAL, est destinée au dépôt et à la diffusion de documents scientifiques de niveau recherche, publiés ou non, émanant des établissements d'enseignement et de recherche français ou étrangers, des laboratoires publics ou privés. 
Is a universal model to describe liquid/liquid extraction of cations by use of ionic liquids at reach?

Isabelle Billard, ${ }^{\mathrm{a}^{*}}$ Ali Ouadi, ${ }^{\mathrm{a}}$ and Clotilde Gaillard ${ }^{\mathrm{b}}$

${ }^{a}$ IPHC-DRS and Strasbourg University, Radiochemistry group, 23 rue du Loess, 67037 Strasbourg Cedex 2, France

${ }^{\mathrm{b}}$ IPN-Lyon, UMR 5822, 4 rue Enrico Fermi, 69622 Villeurbanne Cedex, France

* : corresponding author

A general chemical model describing the extraction mechanism of cations from an acidified aqueous phase toward an ionic liquid phase in which an extracting agent is dissolved is proposed. On this basis, fits are made which recover very satisfactorily the variation of the distribution ratio as a function of $\left[\mathrm{HNO}_{3}\right]$ for several experimental data sets from the literature. This chemical model is discussed and compared to another model.

\section{Introduction}

Liquid/liquid extraction of cationic entities is experiencing a renewed interest from the academic world through the introduction of Ionic Liquids (ILs). ${ }^{1-3}$ These solvents, composed solely of ions, offer some distinctive properties rendering them very appealing: ${ }^{4}$ Most ILs in use display very low vapour pressure and no flammability, by contrast to molecular solvents that often present low flash points and high volatility. In addition, it has been recognized that using ILs in replacement of traditional molecular solvents greatly enhances extraction efficiencies of many well-known extracting agents. ${ }^{5-7}$ Thanks to the increasing number of studies already performed, it is now acknowledged that metal extraction in such systems occurs through an extraction mechanism very different from that at work in molecular solvents. ${ }^{1,8}$ However, the question remains whether extraction in ILs obeys a "universal" chemical scheme or not that could be summarized through the introduction of a limited number of chemical equilibria, as was already done long ago for the extraction of metallic cations towards molecular solvents.

Taking advantage of our experimental work devoted to the extraction of actinides from acidified aqueous phases towards ILs, ${ }^{9,10}$ we propose a general model composed of a set of chemical equilibria, describing the extraction process occurring in aqueous phases/IL phase.

According to this model, fits of experimental D (distribution ratio) variations ${ }^{10-13}$ versus the acidic $\left(\mathrm{HNO}_{3}\right)$ initial concentration of the aqueous phase are performed, demonstrating the very good quantitative agreement between our model and these data. 
Applicability of this model to any extraction system involving cations and IL phases is then discussed and is compared to a second model proposed by another group. ${ }^{11}$

\section{Reference systems}

\subsection{Definitions and systems under study}

In the following, extraction systems of interest will be denoted as: $\mathrm{M}^{\mathrm{m}+} / \mathrm{HX} / \mathrm{E} / \mathrm{IL}$, where $\mathrm{M}^{\mathrm{m}+}$ refers to the cation to be extracted, HX is the acid used, $\mathrm{E}$ is the extracting entity, irrespective of its form (molecular, ionic, protonable or not) and IL is the ionic liquid. A list of acronyms and abbreviations used for the names of the compounds $\mathrm{E}$ can be found at the end of this paper. We will use the term "system" for extraction data obtained with the same cation, same acid, same extracting agent but different ILs, while we will use the term "series" for extraction data obtained for a given IL in a system. In this work, we consider only systems for which no significant extraction is observed for $\mathrm{M}^{\mathrm{m}+} / \mathrm{HX} / / \mathrm{IL}$. In other words, in the systems under study, the extracting agent, $\mathrm{E}$, is responsible for the extraction and the IL solvent acts solely as a reception phase. The cationic and anionic parts of an IL are denoted as $\mathrm{Cat}^{+}$and Ani ${ }^{-}$, respectively. $[\mathrm{X}]$ and $[\bar{X}]$ designate the equilibrium concentration of $\mathrm{X}$ in the aqueous and IL phase, respectively, while subscript "init" refers to the initial values of the concentration.

\subsection{Selected experimental systems}

In order to test our model, we chose two extraction systems for which a rather large set of experimental data is available in the literature. The data we consider are the experimental variations of the extraction ratio, $\mathrm{D}$, as a function of $\left[\mathrm{HNO}_{3}\right]_{\text {init }}$, for a fixed concentration of $\mathrm{E}$. The experimental details of importance to this work are presented in tables 1 and 2.

The first system is $\mathrm{UO}_{2}{ }^{2+} / \mathrm{HNO}_{3} / / \mathrm{TBP} / \mathrm{C}_{1} \mathrm{C}_{\mathrm{n}} \mathrm{imTf}_{2} \mathrm{~N}(\mathrm{n}=4,5,8,10)$, where TBP is tributyl phosphate. The experimental data, redrawn from the works of Dietz et al., ${ }^{12}$ Giridhar et al. $^{13}$ and Billard et al. ${ }^{10}$ are displayed in figure 1 . The second system is $\mathrm{Ca}^{2+} / \mathrm{HNO}_{3} / / \mathrm{DCH} 18 \mathrm{C} 6 / \mathrm{C}_{1} \mathrm{C}_{\mathrm{n}} \operatorname{imTf}_{2} \mathrm{~N}(\mathrm{n}=5,8,10)$, where DCH18C6 is a crown-ether. ${ }^{11}$ The data, redrawn from the work of Hawkins and co-workers, are displayed in figure 2.

These two systems have been chosen because they correspond to different cations and two different extracting agents and also provide interesting experimental features as a function of the alkyl chain length of the IL phase. The "boomerang" variations observed for the system $\mathrm{UO}_{2}{ }^{2+} / \mathrm{HNO}_{3} / / \mathrm{TBP} / \mathrm{C}_{1} \mathrm{C}_{\mathrm{n}} \mathrm{imTf}_{2} \mathrm{~N}(\mathrm{n}=4,5,8,10)$ can be qualitatively described by defining two zones. At low acidities, D is either decreasing or constant as a function of $\left[\mathrm{HNO}_{3}\right]_{\text {init }}$ (regime I), the exact values being dependent of the cationic nature of the IL. Above 
a turnover acidity value, denoted as $[\mathrm{HX}]_{\mathrm{TO}}$, D is sharply increasing as a function of $\left[\mathrm{HNO}_{3}\right]_{\text {init }}$ (regime II). The turnover acidity value depends on the nature of the IL cation, while the D variation in regime II is independent of the IL cation nature.

This boomerang shape is quite common in the literature. Actually, such variations can also be found for $\mathrm{UO}_{2}{ }^{2+} / \mathrm{HNO}_{3} / / \mathrm{TBP} / \mathrm{R}_{1} \mathrm{R}_{2} \mathrm{R}_{3} \mathrm{R}_{4} \mathrm{NTf}_{2} \mathrm{~N}{ }^{14}$ $\mathrm{UO}_{2}{ }^{2+} / \mathrm{HNO}_{3} / /$ diglycolamide/ $\mathrm{C}_{1} \mathrm{C}_{\mathrm{n}} \mathrm{imPF}_{6}(\mathrm{n}=4,6,8)^{15}$ and $\mathrm{UO}_{2}{ }^{2+} / \mathrm{HNO}_{3} / /$ malonamide $/ \mathrm{C}_{1}$ $\mathrm{C}_{4} \operatorname{imTf}_{2} \mathrm{~N}$. ${ }^{9}$ Such a behaviour is not limited to uranyl or $2+$ ions, as $\mathrm{Am}^{3+} / \mathrm{HNO}_{3} / / \mathrm{Cyanex}-$ $272 / \mathrm{C}_{1}-\mathrm{C}_{10} \operatorname{imTf}_{2} \mathrm{~N}^{16}$ or $\mathrm{Am}^{3+} / \mathrm{HNO}_{3} / / \mathrm{T}-\mathrm{DGA} / \mathrm{C}_{1} \mathrm{C}_{\mathrm{n}} \mathrm{imTf}_{2} \mathrm{~N}(\mathrm{n}=4,6,8),{ }^{17} \mathrm{Pu}^{4+} / \mathrm{HNO}_{3} / /$ octyl1,2-HOPO/ $\mathrm{C}_{1} \mathrm{C}_{8} \operatorname{imTf}_{2} \mathrm{~N},{ }^{18} \quad \mathrm{Th}^{4+} / \mathrm{HNO}_{3} / /$ diglycolamide/ $\mathrm{C}_{1} \mathrm{C}_{\mathrm{n}} \mathrm{imPF}_{6} \quad(\mathrm{n}=4, \quad 6, \quad 8),{ }^{19}$ $\mathrm{Pu}^{4+} / \mathrm{HNO}_{3} / / \mathrm{DOAImTf}_{2} \mathrm{~N} / \mathrm{C}_{1} \mathrm{C}_{\mathrm{n}} \mathrm{imTf}_{2} \mathrm{~N}(\mathrm{n}=4,6)^{20}$ and $\mathrm{Pu}^{4+} / \mathrm{HNO}_{3} / / \mathrm{ImPTf}_{2} \mathrm{~N} / \mathrm{C}_{1} \mathrm{C}_{4} \mathrm{imTf}_{2} \mathrm{~N}^{21}$ also evidence a clear boomerang shape. Other examples for $\mathrm{Pu}^{4+}, \mathrm{UO}_{2}{ }^{2+}, \mathrm{Am}^{3+}$ and an impressive list of lanthanide elements can also be found. ${ }^{22-24}$ Therefore, the uranyl data $(n=4$, $5,8,10)$ of this study are representative of a general trend.

The data illustrated in fig. 2 for $\mathrm{Ca}^{2+} / \mathrm{HNO}_{3} / / \mathrm{DCH} 18 \mathrm{C} 6 / \mathrm{C}_{1} \mathrm{C}_{\mathrm{n}} \operatorname{imTf}_{2} \mathrm{~N}(\mathrm{n}=5,8,10)$ also present an evolution of the boomerang shape from $n=5$ to $n=10$ and, in addition, present a shoulder (or levelling) of the $\mathrm{D}$ variation in the approximate acidity range $0.5-3 \mathrm{M}$ for $\mathrm{n}=8$ and 10 , which is thus denoted as regime III. Similar variations with a shoulder have been obtained for $\mathrm{Sr}^{2+}$ and $\mathrm{Ba}^{2+11}$, so that the system we chose is also representative of a rather large wealth of data.

It is our opinion that all data cited above, where the element, the extracting agent and the IL phase are varied, display intrinsic similarities which we believe to be more significant than their differences. To our view, this is more than a coincidence and is the signature for a common mechanism underlying the various extraction profiles, which is accounted for through our model.

\section{Chemical modelling}

\subsection{General model}

There is a list of physical phenomena and chemical reactions that should be considered whatever the extraction mechanism itself could be.

First, the cation, $\mathrm{M}^{\mathrm{m}+}$, may experience complexation with $\mathrm{X}^{-}$, the acid counteranion introduced in the aqueous phase to avoid hydrolysis and precipitation. This acid may be either fully dissociated ( $\mathrm{HCl}, \mathrm{HClO}_{4}$ etc. $)$ or not $\left(\mathrm{HNO}_{3}, \mathrm{H}_{2} \mathrm{SO}_{4}\right.$ etc. $)$.

Second, although the system is biphasic, mutual solubilities of IL and water have been evidenced, together with transfer of acid to the IL phase, even in the absence of $\mathrm{E}^{25}$ 
Therefore, depending on the chemical structure of $\mathrm{E}$, its protonation in the IL phase may be considered, owing to the presence of $\mathrm{H}^{+}$ions arising from acid solubility.

As a consequence, the corresponding equilibria, with their corresponding equilibrium constants $\mathrm{K}_{\mathrm{Z}}$, are written as follows:

- Successive complexations of $\mathrm{M}^{\mathrm{m}+}$ in the aqueous phase:

$$
\left.M^{m+}+i X^{-} \Leftrightarrow\left[M X_{i}\right]^{(m-i)+} \quad(\mathrm{i}=1,2,3 \ldots) \quad \text { (eqs. } 1-\mathrm{i}, \mathrm{K}_{\mathrm{i}}\right)
$$

- Partial dissociation of the acid:

$$
H_{a} X \Leftrightarrow \mathrm{bH}^{+}+H_{(a-b)} X^{b-}
$$

- Protonation of the extracting agent:

$$
\bar{E}+\overline{H^{+}} \Leftrightarrow \overline{\mathrm{EH}^{+}}
$$

Then, we propose the extraction mechanism to proceed through three generic equilibria:

$$
\left.\left[M X_{i}\right]^{(m-i)+}+k \overline{C a t^{+}}+l \overline{H^{+}}+p \bar{E} \Leftrightarrow \overline{\left[M X_{i} E_{p}\right]^{(m-i)+}}+k C a t^{+}+l H^{+} \quad \text { (eqs. } 4-\mathrm{i}, \mathrm{K}_{4-\mathrm{i}}\right)
$$

With $0 \leq \mathrm{i}<\mathrm{m}$ and $(\mathrm{k}+\mathrm{l})=\mathrm{m}-\mathrm{i}$

$$
M^{m+}+(m+i) X^{-}+i \overline{A n i^{-}}+q \bar{E} \Leftrightarrow \overline{\left[M X_{(m+i)} E_{q}\right]^{i-}}+i A n i^{-} \quad \text { (eqs. 5-i, } \mathrm{K}_{5-\mathrm{i}} \text { ) }
$$

With i $>0$

$$
M^{m+}+m X^{-}+r \bar{E} \Leftrightarrow \overline{\left[M X_{m} E_{r}\right]}
$$

This model is an extension of our previous proposal, which we successfully applied to the study of $\mathrm{UO}_{2}{ }^{2+} / \mathrm{HNO}_{3} / / \mathrm{TBP} / \mathrm{C}_{1} \mathrm{C}_{4} \mathrm{imTf}_{2} \mathrm{~N}^{10}$ and $\mathrm{UO}_{2}{ }^{2+} / \mathrm{HNO}_{3} / /$ malonamide $/ \mathrm{C}_{1} \mathrm{C}_{4} \mathrm{imTf}_{2} \mathrm{~N}$. ${ }^{9}$ As compared to this first model, there are three main differences. First, we now consider that all the positively charged complexes $\mathrm{MX}_{\mathrm{i}}^{(\mathrm{m}-\mathrm{i})+}$ might be (but not necessarily are) extracted through a cationic exchange mechanism involving a combination of the $\mathrm{H}^{+}$and $\mathrm{Cat}^{+}$species present in the IL phase (eqs. 4-i), while we previously restricted the extraction of positively charged species to the naked ion $\mathrm{M}^{\mathrm{m}+}$ solely. Second, in a similar way, we consider now all the negatively charged species, $\left[\mathrm{MX}_{(\mathrm{m}+\mathrm{i})}\right]^{-}$to be possibly extracted through an anionic exchange involving i Ani- anions (eqs. 5-i), while we previously restricted the anionic exchange to the sole first negatively charged complex. Third, we also consider the extraction of neutral species (eq. 6), an option that was not included in our two previous attempts. ${ }^{9,}{ }^{10}$ In principle, there should be no need to separate within three different equations $(4,5$ and 6$)$ the extraction process of positively charged, neutral and negatively charged species, but this 
would be at the cost of an increased complexity in the writing and in the number of indices and variables. As such, our model is as general as possible.

In the following subsections, a qualitative discussion of the model is first made, demonstrating its ability to recover the data of the reference systems. Next, we briefly describe and discuss the mathematical and chemical assumptions made in order to derive a mathematically tractable relationship linking $\mathrm{D}$, the distribution ratio, to the experimental $\left[\mathrm{HNO}_{3}\right]_{\text {init }}$ values in view of a quantitative approach to the data. Then, we give details on the programming details and fitting procedure. In the results section, we first present some calculations evidencing the contribution of each extraction equations $(3,4,5$ and 6$)$ to the overall D calculations. Finally, our fitting results for the reference systems are presented, together with a general discussion.

\subsection{Qualitative discussion of the model}

The decrease in $\mathrm{D}$ versus $\left[\mathrm{HNO}_{3}\right]_{\text {init }}$ at low acidities is qualitatively described by the combination of eqs. 1-i plus 4-0 alone. At very low acidities, the metal cation is extracted according to eq. 4-0 but, as $\left[\mathrm{HNO}_{3}\right]_{\text {init }}$ increases, the metallic entity is blocked into non extractable species, thus leading to a decrease of D. On another hand, an increase in D at high acidities is qualitatively described through eqs. 5-i or eq. 6. As $\left[\mathrm{HNO}_{3}\right]_{\text {init }}$ further increases, equations of type 5-i (or 6) become dominant and the presence of $\mathrm{X}^{-}$in the extraction equation leads to an increase in D. Therefore, by simply considering eqs. 1-i, 4-0 and 5-i (or 6), it is possible to qualitatively describe the boomerang shape experimentally observed.

Changing the IL cation to a more hydrophobic one (for example by increasing the alkyl chain length on the imidazolium ring) induces a lower $\mathrm{Cat}^{+}$equilibrium concentration in the aqueous phase, which in turn leads to a lower extraction ratio according to eqs. 4-i (provided $\mathrm{k} \neq 0$ ), as compared to a more soluble $\mathrm{Cat}^{+}$. Consequently, it is expected that $\mathrm{D}$ values at low acidities are decreasing as the hydrophobicity of the IL cation increases. In this case, the dominating character of the anionic (eqs. 5-i) or neutral extractions (eq. 6) becomes evident at lower $\mathrm{HNO}_{3}$ values, so that the turnover concentration is expected to decrease as the hydrophobicity of the IL cation increases. Finally, as the IL cation is not involved in eqs. 5-i and 6, a change in $\mathrm{Cat}^{+}$should not have too much impact onto the extraction at high acidities, provided the IL anion is kept constant. All these features are in perfect qualitative agreement with the experimental ones discussed for the system $\mathrm{UO}_{2}{ }^{2+} / \mathrm{HNO}_{3} / / \mathrm{TBP} / \mathrm{C}_{1} \mathrm{C}_{\mathrm{n}} \mathrm{imTf}_{2} \mathrm{~N}$ (see section 2.2). Qualitative description of $\mathrm{D}$ plots displaying a shoulder as in the case of $\mathrm{Ca}^{2+} / \mathrm{HNO}_{3} / / \mathrm{DCH} 18 \mathrm{C} 6 / \mathrm{C}_{1} \mathrm{C}_{\mathrm{n}} \mathrm{imTf}_{2} \mathrm{~N}(\mathrm{n}=8,10)$ is basically possible on the same pattern, plus the extraction of an intermediate species, through 
eqs. 4-i ( $>$ >). Under this hypothesis, depending on the relative values of all the involved equilibrium constants, there could be a range of $\left[\mathrm{HNO}_{3}\right]_{\text {init }}$ values for which the intermediate species is dominating the aqueous speciation and is thus efficiently extracted, while the extraction of the anionic (or neutral) species through eq. 5-i or eq. 6 is not yet dominant. Under these chemical conditions, a leveling off (i. e. shoulder) of the distribution profile is expected.

We now turn to a quantitative approach of our model.

\subsection{Mathematical modelling}

The chemical system described in section 3.1 can be translated into mathematical equations, following a procedure previously published ${ }^{9}$ and according to a few hypotheses:

1) Activity coefficients are considered to be constant

2) The ligand and $\mathrm{H}^{+}$in the IL phase are in large excess as compared to the metal.

3) The concentrations of $\mathrm{Ani}^{-}$and $\mathrm{Cat}^{+}$in the IL phase are introduced in the equilibrium constants, which are thus conditional equilibrium constants.

Taking account of the activity coefficients for the numerous species of the system is a difficult task. For the aqueous phase, the Specific Interaction Theory (SIT) is a wellestablished procedure, ${ }^{26}$ but faces the problem that there are neither experimental nor tabulated data for the two IL ions, $\mathrm{Cat}^{+}$and $\mathrm{Ani}^{-}$, thus preventing the use of this method. In addition, to the best of our knowledge, there is no theoretical approach to activity coefficients in IL phases so far. We thus decided to assume constant activity coefficients.

The second assumption is in line with chemical conditions usually prevailing in extraction experiments. However, in case of a protonable ligand, it may be envisioned that at very high acidities of the aqueous phase, the protonation constant (eq. 3) is so high that the "free" ligand concentration is no longer in large excess as compared to the initial metal concentration. This leads to an intricate mathematical system which is much more difficult to solve and we thus limit our study to the case of "low" protonation constants, i. e. to free ligand in excess even at the highest acidities investigated in this work, although protonated ligand species can be considered.

\subsection{Program structure, fitting procedure and specific cases investigated}

Under the frame discussed in the above section, one can derive an analytical expression for $\mathrm{D}$, as a function of the initial concentrations of the chemicals and of all the equilibrium constants. This expression is then implemented in a Fortran routine in view of data fitting (i. e. some parameters are set free in a minimization process) or calculations (i. e. all parameters are 
fixed). All fitting results presented here are based on the minimization of the $\chi^{2}$, using the Simplex and Migrad subroutines available on the CERN library, and defined as:

$$
\chi^{2}=\left(\sum \frac{\left(D_{\text {calc }}-D_{\text {exp }}\right)^{2}}{D_{\text {exp }}}\right) / N
$$

Where $\mathrm{N}$ is the number of data points and $\mathrm{D}_{\text {exp }}$ and $\mathrm{D}_{\text {calc }}$ are the experimental and calculated $\mathrm{D}$ values, respectively. The errors associated to the parameter values (see tables 1 and 2) were obtained as the values inducing an increase of $5 \%$ in the $\chi^{2}$. All $\chi^{2}$ values are provided with 3 significant digits.

In a first step, we performed calculations in order to decipher the contributions of some of the equations to the overall $\mathrm{D}$ values. The results are presented in section 4.1. In a second step, we performed fits of the reference systems. The overall number of parameters to be fitted is high. For a +2 charged metal ion, assuming two successive complexations with $\mathrm{X}^{-}$ and extraction of two positively charged, one neutral and one negatively charged species, the total number of parameters amounts to twelve $\left(\mathrm{K}_{1-1}, \mathrm{~K}_{1-2}, \mathrm{~K}_{4-0}, \mathrm{~K}_{4-1}, \mathrm{~K}_{5-1}, \mathrm{~K}_{6}, \mathrm{p}\right.$, p', q, r plus k and k' in eqs. 4-0 and 4-1), notwithstanding of a possible protonation constant for the ligand, $\mathrm{K}_{3}$, while the data sets under study contain 8 to 13 experimental data points. Therefore, we fixed some of the parameters according to the following considerations:

i) Only two successive uranyl-nitrate complexes have been evidenced in the literature, ${ }^{27}$ thus equations of type 1-i are restricted to 1-1 (formation of the positively charged species $\left.\left[\mathrm{UO}_{2}\left(\mathrm{NO}_{3}\right)\right]^{+}\right)$and 1-2 (formation of the neutral species $\left.\left[\mathrm{UO}_{2}\left(\mathrm{NO}_{3}\right)_{2}\right]\right)$. In the case of calcium, only one nitrate complex is known ${ }^{27}$ thus limiting the model to eq. 1-1 (formation of $\left.\left[\mathrm{Ca}\left(\mathrm{NO}_{3}\right)\right]^{+}\right)$. These successive nitrate complexation constants have been fixed to their thermodynamical published values. ${ }^{27}$ In addition, we will consider $\mathrm{HNO}_{3}$ to be fully dissociated.

ii) Both TBP and DCH18C6 are assumed to be non protonable moieties in ILs, so that $\mathrm{K}_{3}$ is set to zero in eq. 3. TBP protonation in molecular solvents is well-known and so is crown-ethers protonation. However, considering the ionic nature of ILs, the situation might be different in such media and it would be difficult to assign a specific structural form to the extracted acid, if any. Our previous study on the effect of TBP onto acid extraction ${ }^{25}$ has shown that TBP $\left(1.1 \mathrm{M}_{\text {in }} \mathrm{C}_{1} \mathrm{C}_{4} \mathrm{imTf}_{2} \mathrm{~N}\right)$ has only a slight effect onto $\mathrm{HNO}_{3}$ extraction (i. e. as compared to the quantities that are solubilised in the IL phase in the absence of TBP) and that this effect is hardly visible, owing to experimental uncertainties, below $\left[\mathrm{HNO}_{3}\right]_{\text {init }}=7.5 \mathrm{M}$. To the best of our knowledge, there are no similar data for DCH18C6 but we note that for the 
ligand concentration of this work $([\mathrm{DCH} 18 \mathrm{C} 6]=0.1 \mathrm{M})$ the depletion in $\mathrm{H}^{+}$in the aqueous phase due to a possible ligand protonation would also be hardly detectable through titration. Therefore, we think it is justified both on an applied logic (number of parameters) and on an experimental basis to neglect ligand protonation in this work. Note however that the specific effect of ligand protonation is investigated in sect. 4.1.

iii) As such, the model accounts for several ligand stoichiometries in the extracted complexes ( $\mathrm{p}, \mathrm{q}$ and $\mathrm{r}$ in eqs. 4-i, 5-i and 6). However, as the data sets under investigations have all been acquired for fixed initial ligand concentrations, parameters $\mathrm{p}, \mathrm{q}$ and $\mathrm{r}$ cannot be reasonably fitted from these data alone. All these parameters have thus been fixed to 1 . As a consequence, the associated equilibrium constants become conditional constants that should not be over interpreted.

iv) The initial concentration of TBP and DCH18C6, together with the initial concentrations of $\mathrm{UO}_{2}{ }^{2+}$ and $\mathrm{Ca}^{2+}$, have been fixed to the published experimental values. Concentrations of uranium or calcium indicated in the references as "at the trace level" have been arbitrarily fixed at $10^{-7} \mathrm{M}$. In agreement with data previously published for $\mathrm{C}_{1} \mathrm{C}_{4} \operatorname{imTf}_{2} \mathrm{~N},{ }^{9,}{ }^{25}$ we assume that $\overline{\left[\mathrm{H}^{+}\right]}$is a linear increasing function of $\left[\mathrm{HNO}_{3}\right]_{\text {init. }}$ We also assume the slope of this variation to be identical for all the ILs under consideration in this work, and we fix the ratio value to 0.94 , ie:

$\frac{\overline{\left[H^{+}\right]}}{\left[H^{+}\right]}=0.94$

v) The solubility of $\mathrm{Tf}_{2} \mathrm{~N}^{-}$in water as a function of $\left[\mathrm{HNO}_{3}\right]_{\text {init }}$ has been measured in $\mathrm{C}_{1} \mathrm{C}_{4} \mathrm{imTf}_{2} \mathrm{~N}$ according to a procedure described in the supplementary materials. The experimental variation (see supplementary material) was fitted with a linear law and the solubility of $\mathrm{Tf}_{2} \mathrm{~N}^{-}$in the other ILs was assumed to obey the same linear law, i.e: $\left[\mathrm{Tf}_{2} \mathrm{~N}^{-}\right]=9.1 \times 10^{-3}\left[\mathrm{HNO}_{3}\right]_{\text {init }}+1.5 \times 10^{-3}$

Finally, we limited the possible extraction equilibria to 4-0, 4-1, 5-1 and 6 only. According to these assumptions, the number of parameters is thus decreased to $6\left(\mathrm{~K}_{4-0}, \mathrm{~K}_{4-1}\right.$, $\mathrm{K}_{5-1}, \mathrm{~K}_{6}$, $\mathrm{k}$ in eq. 4-0 and its equivalent k' in eq. 4-1). The latter two have been allowed to take integer values only. Each series has been fitted independently and various trials have been performed. In particular, apart from the "general" fits with all parameters liable to variation, we also performed "limited" fits, for which some of the equilibrium constants were set to zero to investigate the effect of a restricted model onto the goodness of the fits.

\section{Results and discussion}




\subsection{Individual contributions to the model}

In Figs. 3 to 5, we present the calculated D variations for various "ideal" cases that are documented in Table 3. Figure 3 is dedicated to the contributions of equation 4-0 or equation 5-1 as the unique extraction equilibrium, to the effect of equations 4-0 and 5-1 taken together and to a comparison with eq. 6 alone. For all these calculations, two successive complexation equilibria in the aqueous phase have been additionally considered, that mimic the realistic uranyl case. The qualitative description given in section 3.2 for the boomerang shape and the change in $\left[\mathrm{HNO}_{3}\right]_{\mathrm{TO}}$ is in close connection with the plots. Furthermore, it can be seen that eq. 6 alone is not equivalent to eqs. $4-0$ and 5-1 taken together. This is due to two main reasons: in eq. 6, neither $\left[\mathrm{Cat}^{+}\right]$nor [Ani $]$are implied, while these quantities have an impact in eqs. 40 and 5-1 through the variations expressed in eq. 9, and the different stoichiometric coefficients for $\mathrm{X}^{-}$(2 in eq. 6 and 3 in eq. 5-1) are directly related to the slope of the D increase as a function of $[\mathrm{HX}]_{\text {init }}$.

Then, Figures 4 and 5 present the effect of the ligand protonation, for an ideal case close to the uranyl system (Fig. 4) or to the calcium case (Fig. 5). For $K_{3}=0$, the shoulder obtained is in line with the quantitative description in section 3.2. As $\mathrm{K}_{3}$ is increased, the concentration of the free ligand is decreasing in the whole acidic range so the D values decrease, even at the lowest acidity of the aqueous phase. In Fig. 4, increasing the protonation of the ligand leads to an opening of the boomerang angle, a situation that has already been experimentally observed in the system $\mathrm{UO}_{2}{ }^{2+} / \mathrm{HNO}_{3} / /$ malonamide $/ \mathrm{C}_{1} \mathrm{C}_{4} \mathrm{imTf}_{2} \mathrm{~N}$. ${ }^{9}$ In Fig. 5, the protonation of the ligand has a dramatic impact onto the $\mathrm{D}$ values at high acidities so that eventually the D plot resembles the traditional bell shape obtained in molecular solvents. In view of fitting boomerang shapes as illustrated in fig. 1, the data plotted in Figs. 4 and 5 a posteriori justify neglecting $\mathrm{K}_{3}$.

\subsection{Fittings}

Tables 1 (uranyl case) and 2 (calcium case) display all the fitted values and the relevant data while Figs. 1 and 2 present the fitted curves together with the experimental data sets. In the tables, the $\chi^{2}$ values have been limited to three significant digits. In some cases, the fitting routine converges solely with a nil value of some of the parameters. These are indicated in the tables under the notation "ltz" (lowered to zero). For $\mathrm{Ca}^{2+} / \mathrm{HNO}_{3} / / \mathrm{DCH} 18 \mathrm{C} 6 / \mathrm{C}_{1} \mathrm{C}_{10} \mathrm{imTf}_{2} \mathrm{~N}$, allowing all parameters to be free leads to convergence problems, due to a strong correlation between $\mathrm{K}_{6}$ and $\mathrm{K}_{5-1}$, while the other parameters appear to be reasonably defined. Therefore, we performed two different fits, one fixing $\mathrm{K}_{6}=0$ and the other one fixing $\mathrm{K}_{5-1}=0$. These 
two parameter sets gave almost identical $\chi^{2}$ values (less than $2 \%$ relative difference) and almost indistinguishable plots.

As can be seen, the fits recover quite nicely the experimental trends for all the series.

\subsection{Discussion}

\section{Uranium system:}

Although obtained for rather different metal concentrations and at two different research groups, the two series for $\mathrm{C}_{1} \mathrm{C}_{4} \mathrm{imTf}_{2} \mathrm{~N}$ give similar fitted values, which indicate good data quality. The $\mathrm{K}_{4-0}$ values significantly decrease as a function of $\mathrm{n}$, the alkyl chain length, until the value is set to zero by the fitting routine. For $n=10$, the cancellation of $K_{4-0}$ is compensated by the extraction of a +1 charged species, through $\mathrm{K}_{4-1}$. As the number of exchanged $\mathrm{H}^{+}$remains constant to 0 from $\mathrm{n}=4$ to 10 , this corresponds to an extraction mechanism evolving from exchange of two IL cations for $n=4,5,8$ to one single IL cation for the more hydrophobic IL cation $(n=10)$. It has to be recalled that the extraction of positively charged species occurs solely at low acidities of the aqueous phase. Under these chemical conditions, the quantity of $\mathrm{H}^{+}$present in the IL phase is low, whatever the IL, and although the hydrophobicity of the IL cation increases with the alkyl chain length, the system seems to favor exchange of IL cations, in large excess, rather than exchange of $\mathrm{H}^{+}$, that are present in small quantities. However, this lowering of $\mathrm{K}_{4-0}$ could also be interpreted as the evidence for a difference in the solvation energy of the $\left[\mathrm{UO}_{2} \cdot \mathrm{pTBP}\right]^{2+}$ species in the various ILs. It is probable that these two effects contribute to the lowering of $\mathrm{D}$ as a function of $\mathrm{n}$ at low acidity. Conversely, the fact that a unique $\mathrm{K}_{5-1}$ value is able to account for all the data in Fig. 1 (average value: $6.2 \times 10^{-2}$ ) would indicate that the solvation energy of the species $\left[\mathrm{UO}_{2}\left(\mathrm{NO}_{3}\right)_{3} \text {.qTBP] }\right]^{-}$is more or less identical, whatever the IL. Finally, it is interesting to note that extraction of a neutral species is not to be considered in this system, whatever the IL. This is in line with the spectroscopic evidences that have been provided, demonstrating that the uranyl neutral species $\left[\mathrm{UO}_{2}\left(\mathrm{NO}_{3}\right)_{2} .2 \mathrm{TBP}\right]$ is not present in extracted IL phases. ${ }^{10,14} \mathrm{As}$ mentioned previously, the data investigated here do not allow determining the exact values of $\mathrm{k}$ and $\ell$ in eqs. 4 -i. In order to get some insight onto this question, measuring the $\mathrm{D}$ variation at a fixed acidity, as a function of added $\mathrm{C}_{1} \mathrm{C}_{\mathrm{n}} \mathrm{imCl}$ in the aqueous phase is needed. ${ }^{1,2}$ To the best of our knowledge, such an experimental test has not been performed yet for the system $\mathrm{UO}_{2}{ }^{2+} / \mathrm{HNO}_{3} / / \mathrm{TBP} / \mathrm{C}_{1} \mathrm{C}_{\mathrm{n}} \mathrm{imTf}_{2} \mathrm{~N}$. In $\mathrm{UO}_{2}{ }^{2+} / \mathrm{HNO}_{3} / / \mathrm{TBP} /\left(\mathrm{CH}_{3}\right)_{3} \mathrm{NCH}_{2} \mathrm{CH}_{2} \mathrm{OMeTf}_{2} \mathrm{~N}$, the cationic exchange has been proved to proceed through exchange of one $\mathrm{H}^{+}$and one $\mathrm{Cat}^{+},{ }^{14}$ but such a result cannot be transferred to our system with full confidence, owing to the differences in the hydrophilicity of the two ILs. 
Calcium system: The situation is more intricate in this case. In particular, for the last series $\left(\mathrm{C}_{1} \mathrm{C}_{10} \mathrm{imTf}_{2} \mathrm{~N}\right), \mathrm{K}_{6}$ is needed to recover the experimental variations, which was not the case for the uranyl system. It was not necessary to assume extraction of the first calcium-nitrato complex in $\mathrm{C}_{1} \mathrm{C}_{5} \operatorname{imTf}_{2} \mathrm{~N}$ to fit the data, while the experimental variations could not be reproduced without this assumption for $\mathrm{n}=8$ and 10. The speciation calculated in the IL phase from the fits $(\mathrm{n}=8$ or 10$)$ shows that below $\left[\mathrm{HNO}_{3}\right]_{\text {init }}=0.1 \mathrm{M}$, the dominating extracted species is [Ca.pDCH18C6 $]^{2+}$, while $\left[\mathrm{Ca}\left(\mathrm{NO}_{3}\right) \cdot \mathrm{qDCH} 18 \mathrm{C} 6\right]^{+}$is dominant in the range ca. 0.1 $\mathrm{M}$ up to 2-3 $\mathrm{M}$, above which the main species is either $\left.\mathrm{Ca}\left(\mathrm{NO}_{3}\right)_{3} \cdot \mathrm{rDCH} 18 \mathrm{C6}\right]^{-}$( $\mathrm{n}$ $=5,8)$ or $\left[\mathrm{Ca}\left(\mathrm{NO}_{3}\right)_{2} \cdot \mathrm{rDCH} 18 \mathrm{C} 6\right](\mathrm{n}=10)$. It is quite difficult to interpret this result and the reasons why $\mathrm{C}_{1} \mathrm{C}_{\mathrm{n}} \mathrm{imTf}_{2} \mathrm{~N} \quad(\mathrm{n}=8$ or 10) would accommodate the species $\left[\mathrm{CaNO}_{3} \cdot \mathrm{pDCH} 18 \mathrm{C} 6\right]^{+}$better than $\mathrm{C}_{1} \mathrm{C}_{5} \mathrm{imTf}_{2} \mathrm{~N}$ remains unclear at the moment.

In addition, change in the $\ell$ values for $\mathrm{K}_{4-0}$, corresponding to a change in the nature of the exchanged cations, makes comparison from one set of fitted values to another quite difficult. However, by comparison of the uranyl and calcium cases, we note that $\mathrm{C}_{1} \mathrm{C}_{5} \operatorname{imTf}_{2} \mathrm{~N}$ favors IL cation exchange whatever the metal/extracting agent couple, while $\mathrm{C}_{1} \mathrm{C}_{8} \operatorname{imTf}_{2} \mathrm{~N}$ and $\mathrm{C}_{1} \mathrm{C}_{10} \operatorname{imTf}_{2} \mathrm{~N}$ accommodate both $\mathrm{IL}$ cation and $\mathrm{H}^{+}$exchanges in the presence of calcium/DCH18C6 but only IL cation exchange in the presence of uranyl/TBP. Considering the identical charges of the metallic cations of this study, and the very similar complexation constants $\mathrm{K}_{1-1}$ for the two, such a difference should rather be ascribable to the difference in the ligand but the physical reasons are unclear.

Finally, the major difference between the calcium and uranyl systems is the appearance of neutral extraction for calcium in $\mathrm{C}_{1} \mathrm{C}_{10} \mathrm{imTf}_{2} \mathrm{~N}$. Again, the reason why this is not true for the uranyl system is not understood at the moment, although it is most probably related to the ligand rather than to the metallic entity.

General discussion: Our chemical model is able to reproduce the experimental variations of the two chosen systems. In particular, the model is able to reproduce the changes in the D vs $\left[\mathrm{HNO}_{3}\right]_{\text {init }}$ pattern as a function of the nature of the IL cation, as depicted in figs. 1 and 2, with extraction mechanisms of variable importance. Although this success does not prove that this model is a fully correct description of the extraction processes actually occurring, it is nevertheless a very encouraging result.

Another suggestion has been made, in view of qualitatively describing the extraction data for $\mathrm{Ca}^{2+}$ discussed in the present work, together with similar data obtained for $\mathrm{Sr}^{2+}, \mathrm{Ba}^{2+}$ and for +1 ions $\left(\mathrm{Na}^{+}, \mathrm{K}^{+}, \mathrm{Cs}^{+}\right) .{ }^{11,28,29}$ This proposal is based on three distinct pathways. Two of them correspond to cationic exchange, either with $\mathrm{H}^{+}$or $\mathrm{Cat}^{+}$ions and the third one 
corresponds to ion pairing, (i.e. extraction of a neutral species) the relative balance between the three pathways being dependent on the chemical conditions (IL nature, ion to be extracted, nature of E etc.). Obviously, two of the suggested exchange processes, i. e. cationic exchange through $\mathrm{H}^{+}$and cationic exchange through $\mathrm{Cat}^{+}$, correspond to our proposal. In fact, these authors categorize cationic exchange under two different equations (i.e. pathways), while we merge these two in the more general equation written in the form of eq. 4-i. In this sense, we consider that the two models perfectly agree on the question of cationic exchange. Note however that our model accounts for mixed cationic exchange of the type $\mathrm{k} \mathrm{H}^{+}$and $\ell \mathrm{Cat}^{+}$and takes into account extraction of +3 or +4 ions, such as $\mathrm{Am}^{3+}$ or $\mathrm{Pu}^{4+}$, thus being more general than the one proposed by Dietz and co-workers.

Clearly, the irreducible difference between the two models lies in the proposal of either ion pairing alone or anionic exchange together with ion pairing. Besides, the two proposals are in qualitative agreement with the data discussed in the present work, because under the assumption of ion pairing between $\mathrm{M}^{2+}$ and two nitrate ions, an increase in the nitric acid concentration will lead to an increase in $\mathrm{D}$, as in the case of anionic exchange involving three nitrates, as demonstrated through our simulations. However, as clearly shown in fig. 3, the slope of the D increase depends on the assumption made and, in the case of the uranyl system and in two out of three of the calcium series, our study shows that ion pairing is not occurring, while anionic exchange has to be considered to recover the data.

The difference between the two models is more than anecdotal because following one or the other of the two hypotheses, very different ways to tackle the question of pollution of the aqueous phase by IL solubilization as a by-side effect of the extraction mechanism can be envisioned. If ion pairing occurs alone, then one should always favor this mechanism, by using ILs with long alkyl side-chains ${ }^{30}$ and/or fluorinated anions. ${ }^{31}$ Attempts performed under these lines did not prove to be very efficient, possibly indicating that ion pairing is not a dominant mode of extraction, whatever the IL chosen. Actually, we also note that $\mathrm{Ca}^{2+} / \mathrm{HNO}_{3} / / \mathrm{DCH} 18 \mathrm{C} 6 / \mathrm{C}_{1} \mathrm{C}_{10} \mathrm{imTf}_{2} \mathrm{~N}$ is the less efficient system in view of $\mathrm{Ca}$ (II) extraction, at any acidities. Furthermore, this implies that extraction should always be performed at the highest achievable acidities in order for ion pairing to be dominant over cationic exchange and to get reasonable extraction distribution ratios. This may prove to be irrelevant in some industrial envisioned cases. By contrast, if anionic exchange can substitute to cationic exchange at high acidities, then ion exchange cannot be avoided but one may take advantage of it following two different strategies. First, one may favor cationic exchanges involving cheap sacrificial ions, introduced on purpose in the IL phase, such as $\mathrm{Na}^{+}$or $\mathrm{NH}_{4}^{+}$. Attempts 
in this way have already been performed and proved to be quite efficient, although not replacing $\mathrm{Cat}^{+}$back transfer up to $100 \% .{ }^{32}$ Second, one may also observe that the best sacrificial ion is $\mathrm{H}^{+}$, which is already present in the IL in large amounts, thus not requiring any additional chemical to be introduced in the system. In view of system optimization, one has to understand in details the reasons driving the cationic exchange through either $\mathrm{m} \mathrm{Cat}^{+}$, ${ }^{33} \mathrm{~m} \mathrm{H}^{+}, 9,34$ or mixed $\mathrm{Cat}^{+} / \mathrm{H}^{+9,14}$ exchange as already been observed in the literature, in order to conceive extraction systems occurring with $\mathrm{H}^{+}$exchange only.

\section{Conclusion}

We propose a chemical model, based on cationic, neutral and anionic exchange, which is able to recover a large number of extraction data for systems of the form $\mathrm{M}^{\mathrm{m}+} / \mathrm{HX} / \mathrm{E} / \mathrm{IL}$. The restricted version of this model proposed by other authors and solely considering cationic and ion pairing, appears to be insufficient to quantitatively describe the $\mathrm{UO}_{2}{ }^{2+} / \mathrm{HNO}_{3} / / \mathrm{TBP} / \mathrm{C}_{1} \mathrm{C}_{\mathrm{n}} \mathrm{imTf}_{2} \mathrm{~N}$ system, and part of the $\mathrm{Ca}^{2+} / \mathrm{HNO}_{3} / / \mathrm{DCH} 18 \mathrm{C} 6 / \mathrm{C}_{1} \mathrm{C}_{\mathrm{n}} \mathrm{imTf}_{2} \mathrm{~N}$ system. Actually, spectroscopic data have already proved that the extracted species at high acidities in $\mathrm{UO}_{2}{ }^{2+} / \mathrm{HNO}_{3} / / \mathrm{TBP} / \mathrm{IL}^{10,14}$ differs from the neutral $\mathrm{UO}_{2}\left(\mathrm{NO}_{3}\right)_{2} \cdot \mathrm{TBP}_{2}$ extracted in dodecane, ${ }^{10,14}$ thus confirming the need of anionic exchange at high acidities at least for some cases but the relative experimental abundances of the two models is still unknown, which will require a lot of additional experimental work. Spectroscopic studies appear to be a very promising way to solve this question and more work on this topic is underway in our group.

\section{List of acronyms and abbreviations used.}

$\mathrm{C}_{1} \mathrm{C}_{\mathrm{n}} \mathrm{im}^{+}$:1-methyl, 3-n-alkyl imidazolium

CMPO: octyl(phenyl)- $N, N$-diisobutylcarbamoylmethyl(phosphine oxide)

Cyanex-272: commercial compound, based on phosphinic acid

DCH18C6: dicyclohexano-18-crown-6 ether

HOPO: 2-hydroxypyridine- $N$-oxide

$\operatorname{ImPTf}_{2} \mathrm{~N}$ : diethyl-2-(3-methylimidazolium)ethylphosphonate $\mathrm{Tf}_{2} \mathrm{~N}$

$\mathrm{R}_{1} \mathrm{R}_{2} \mathrm{R}_{3} \mathrm{R}_{4} \mathrm{~N}^{+}$: tetraalkylammonium ion

TBP: tributyl phosphate

$\mathrm{Tf}_{2} \mathrm{~N}^{-}$: bis(trifluoromethanesulfonyl)imide

T-DGA: tripodal diglycolamide 
TODGA: tetraoctyldiglycolamide

DOAImTf $_{2} \mathrm{~N}$ : N,N-dioctyl-2-(3-methylimidazolium) $\mathrm{Tf}_{2} \mathrm{~N}$

\section{Acknowledgments}

The financial support of the French program ANR is greatly acknowledged (LILAT project).

Dr. M. Sypula is thanked for the NMR data.

\section{References}

1. I. Billard, A. Ouadi and C. Gaillard, Anal. Bioanal. Chem., 2011, 400, 1555-1566.

2. I. Billard, in Handbook on the Physics and Chemistry of Rare earth, eds. J. C. G. Bünzli and V. K. Percharsky, Elsevier, 2013, vol. 43, ch. 256.

3. K. Binnemans, Chem. Rev., 2007, 107, 2592.

4. Wasserscheid, P., Welton and T., Ionic liquids in synthesis, Wiley-VCH, Weinheim, 2008.

5. S. Dai, Y. H. Yu and C. E. Barnes, J. Chem. Soc., Dalton Trans., 1999, 1201.

6. K. Nakashima, F. Kubota, T. Maruyama and M. Goto, Ind. Eng. Chem. Res., 2005, 44, 4368.

7. A. N. Turanov, V. V. Karandashev and V. E. Baulin, Solv. Ext. Ion Exchange, 2008, 26, 77-99.

8. M. L. Dietz, Sep. Sci. Technol., 2006, 41, 2047.

9. M. Bonnaffé-Moity, A. Ouadi, V. Mazan, S. Miroshnichenko, D. Ternova, S. Georg, M. Sypula, C. Gaillard and I. Billard, Dalton Trans., 2012, 41, 7526-7536.

10. I. Billard, A. Ouadi, E. Jobin, J. Champion, C. Gaillard and S. Georg, Solv. Ext. Ion Exchange, 2011, 29, 577-601.

11. C. A. Hawkins, S. L. Garvey and M. L. Dietz, Sep. Pur. Technol. , 2012, 89, 31-38.

12. M. L. Dietz and D. C. Stepinski, Talanta, 2008, 75, 598.

13. P. Giridhar, K. Venkatesan, S. Subramaniam, T. G. Srinivasan and P. R. V. Rao, J. Alloys. Compds., 2008, 448, 104.

14. T. J. Bell and Y. Ikeda, Dalton Trans., 2011, 40, 10125-10130.

15. Y. Shen, X. Tan, L. Wang and W. Wu, Sep. Pur. Technol., 2011, 78, 298-302.

16. V. A. Cocalia, M. P. Jensen, J. D. Holbrey, S. K. Spear, D. C. Stepinski and R. D. Rogers, Dalton Trans., 2005, 1966.

17. A. Sengupta, P. K. Mohapatra, M. Iqbal, W. Verboom, J. Huskens and S. V. Godbole, RSC Advances, 2012, 2, 7492-7500.

18. V. A. Cocalia, J. D. Holbrey, K. E. Gutowski, N. J. Bridges and R. D. Rogers, Tsinghua Science and Technology, 2006, 11, 188.

19. Y. Shen, S. Wang, L. Zhu, J. Wang and W. Wu, Ind. Eng. Chem. Res., 2011, 50, 13990-13996.

20. A. Rout, K. A.Venkatesan, T. G. Srinivasan and P. R. V. Rao, Sep. Pur. Technol., 2012, 97, 164-171.

21. Rout, A., Venkatesan, K., Srinivasan, T. G., V. Rao and P. R., Radiochim. Acta, 2010, 98, 459.

22. A. Rout, K. A. Venkatesan, T. G. Srinivasan and P. R. V. Rao, J. Hazardous Mat., 2012, 221-222, 62-67. 
23. A. Rout, K. Venkatesan, T. G. Srinivasan and P. R. V. Rao, Solv. Ext. Ion Exchange, 2011, 29, 602-618.

24. M. E. Mincher, D. L. Quach, Y. J. Liao, B. J. Mincher and C. M. Wai, Solv. Ext. Ion Exchange, 2012, 30, 735-747.

25. C. Gaillard, V. Mazan, S. Georg, O. Klimchuk, M. Sypula, I. Billard, R. Schurhammer and G. Wipff, Phys. Chem. Chem. Phys., 2012, 14, 5187-5199.

26. Guillaumont, R., Fanghanel, T., Fuger, J., Grenthe, I., Neck, V., Palmer, D. A., Rand and M. H., Update on the chemical thermodynamics of uranium, neptunium, plutonium, americium and technetium, Elsevier, Amsterdam, 2003.

27. N. A. Lange and J. A. Dean, Lange's handbook of chemistry, McGraw-Hill, Montréal, 1999.

28. M. L. Dietz, J. A. Dzielawa, I. Laszak, B. A. Young and M. P. Jensen, Green Chem., 2003, 5, 682.

29. M. L. Dietz and D. C. Stepinski, Green Chem., 2005, 7, 747.

30. D. C. Stepinski, M. P. Jensen, J. A. Dzielawa and M. L. Dietz, Green Chem., 2005, 7, 151.

31. H. Heitzman, B. A. Young, D. J. Rausch, P. Rickert, D. C. Stepinski and M. L. Dietz, Talanta, 2006, 69, 527.

32. H. Luo, S. Dai, P. V. Bonnesen, A. C. Buchanan, J. D. Holbrey, N. J. Bridges and R. D. Rogers, Anal. Chem., 2004, 76, 3078.

33. K. Shimojo, K. Kurahashi and H. Naganawa, Dalton Trans., 2008, 5083.

34. F. Kubota, Y. Shimobori, Y. Baba, Y. Koyanagi, K. Shimojo, N. Kamiya and M. Goto, J. Chem. Eng. Japan, 2011, 44, 307-312.

35. I. Billard, C. Gaillard and C. Hennig, Dalton Trans., 2007, 4214. 


\begin{tabular}{|c|c|c|c|c|c|c|c|c|c|c|}
\hline IL phase & {$\left[\mathrm{M}^{\mathrm{m}+}\right](\mathrm{M})$} & [E] $(\mathrm{M})$ & $\mathrm{K}_{4-0}$ & $\ell$ for $K_{4-0}$ & $\mathrm{~K}_{4-1}$ & $\ell$ for $K_{4-1}$ & $\mathrm{~K}_{5-1}$ & $\mathrm{~K}_{6}$ & $\chi^{2}$ & ref. \\
\hline $\mathrm{C}_{1} \mathrm{C}_{4} \mathrm{imTf}_{2} \mathrm{~N}$ & $4.2 \times 10^{-4^{*}}$ & & $\begin{array}{c}1.4 \times 10^{-3} \\
\left( \pm 0.2 \times 10^{-3}\right)\end{array}$ & \multirow{4}{*}{ s } & \multirow{4}{*}{ ltz } & \multirow{4}{*}{ n. a. } & $\begin{array}{c}6.2 \times 10^{-2} \\
\left( \pm 0.6 \times 10^{-2}\right)\end{array}$ & \multirow{5}{*}{ ltz } & $8.58 \times 10^{-2}$ & 13 \\
\hline $\mathrm{C}_{1} \mathrm{C}_{4} \mathrm{imTf}_{2} \mathrm{~N}$ & $10^{-3 *}$ & $1.1^{*}$ & $\begin{array}{c}9 \times 10^{-4} \\
\left( \pm 1 \times 10^{-4}\right)\end{array}$ & & & & $\begin{array}{c}6.7 \times 10^{-2} \\
\left( \pm 0.7 \times 10^{-2}\right)\end{array}$ & & $7.91 \times 10^{-2}$ & 10 \\
\hline $\mathrm{C}_{1} \mathrm{C}_{5} \operatorname{imTf}_{2} \mathrm{~N}$ & \multirow{3}{*}{$10^{-7}$} & \multirow{3}{*}{$1.2^{*}$} & $\begin{array}{c}6.8 \times 10^{-4} \\
\left( \pm 0.9 \times 10^{-4}\right)\end{array}$ & & & & $\begin{array}{c}6.5 \times 10^{-2} \\
\left( \pm 0.7 \times 10^{-2}\right)\end{array}$ & & $1.08 \times 10^{-1}$ & \multirow{3}{*}{12} \\
\hline $\mathrm{C}_{1} \mathrm{C}_{8} \mathrm{imTf}_{2} \mathrm{~N}$ & & & $\begin{array}{c}3.4 \times 10^{-5} \\
\left( \pm 0.4 \times 10^{-5}\right)\end{array}$ & & & & $\begin{array}{c}5.9 \times 10^{-2} \\
\left( \pm 0.6 \times 10^{-2}\right)\end{array}$ & & $6.83 \times 10^{-2}$ & \\
\hline $\mathrm{C}_{1} \mathrm{C}_{10} \mathrm{imTf}_{2} \mathrm{~N}$ & & & ltz & n. a. & $\begin{array}{c}3 \times 10^{-5} \\
\left( \pm 2 \times 10^{-5}\right)\end{array}$ & 0 & $\begin{array}{c}5.6 \times 10^{-2} \\
\left( \pm 0.6 \times 10^{-2}\right)\end{array}$ & & $6.97 \times 10^{-2}$ & \\
\hline
\end{tabular}

Table 1. Uranyl case. For all the fits: $\mathrm{K}_{1-1}=1.99$ and $\mathrm{K}_{1-2}=0.07 ; \mathrm{p}=\mathrm{q}=\mathrm{r}=1 ; \mathrm{K}_{5-2}=0 . \mathrm{K}_{3}=0$ (see text). *: as from the reference paper.

ltz: lowered to zero by the fitting program

n. a.: not applicable 


\begin{tabular}{|c|c|c|c|c|c|c|c|c|c|c|}
\hline IL phase & {$\left[\mathrm{M}^{\mathrm{m}+}\right](\mathrm{M})$} & {$[\mathrm{E}](\mathrm{M})$} & $\mathrm{K}_{4-0}$ & $\ell$ for $K_{4-0}$ & $\mathrm{~K}_{4-1}$ & $\ell$ for $K_{4-1}$ & $\mathrm{~K}_{5-1}$ & $\mathrm{~K}_{6}$ & $\chi^{2}$ & ref. \\
\hline $\mathrm{C}_{1} \mathrm{C}_{5} \mathrm{imTf}_{2} \mathrm{~N}$ & \multirow{4}{*}{$10^{-7}$} & \multirow{4}{*}{$10^{-1^{*}}$} & $\begin{array}{c}2.4 \times 10^{-4} \\
\left( \pm 0.3 \times 10^{-4}\right)\end{array}$ & 0 & ltz & n. a. & $\begin{array}{c}1.7 \times 10^{-3} \\
\left( \pm 0.3 \times 10^{-3}\right)\end{array}$ & \multirow{3}{*}{ ltz } & $7.69 \times 10^{-2}$ & \multirow{4}{*}{11} \\
\hline \multirow{2}{*}{$\mathrm{C}_{1} \mathrm{C}_{8} \operatorname{imTf}_{2} \mathrm{~N}$} & & & $\begin{array}{c}8 \times 10^{-3} \\
\left( \pm 1 \times 10^{-3}\right)\end{array}$ & 1 & $\begin{array}{c}6.2 \times 10^{-2} \\
\left( \pm 0.7 \times 10^{-2}\right)\end{array}$ & \multirow{3}{*}{1} & $5.4 \times 10^{-4}$ & & \multirow{2}{*}{$3.84 \times 10^{-2}$} & \\
\hline & & & $\begin{array}{c}9 \\
( \pm 1) \\
\end{array}$ & 2 & $\begin{array}{c}5.7 \times 10^{-2} \\
\left( \pm 0.7 \times 10^{-2}\right)\end{array}$ & & $\left( \pm 0.5 \times 10^{-4}\right)$ & & & \\
\hline $\mathrm{C}_{1} \mathrm{C}_{10} \mathrm{imTf}_{2} \mathrm{~N}$ & & & $\begin{array}{c}3.1 \times 10^{-6} \\
\left( \pm 0.7 \times 10^{-6)}\right.\end{array}$ & 0 & $\begin{array}{c}4.3 \times 10^{-2} \\
\left( \pm 0.7 \times 10^{-2)}\right.\end{array}$ & & 0 & $\begin{array}{c}4.8 \times 10^{-2} \\
\left( \pm 0.6 \times 10^{-2}\right)\end{array}$ & $5.40 \times 10^{-2}$ & \\
\hline
\end{tabular}

Table 2. Calcium case. For all the fits: $\mathrm{K}_{1-1}=1.9$ and $\mathrm{K}_{1-2}=0 ; \mathrm{p}=\mathrm{q}=\mathrm{r}=1 ; \mathrm{K}_{5-2}=0 . \mathrm{K}_{3}=0$ (see text).

$*$ : as from the reference paper.

ltz: lowered to zero by the fitting program

n. a.: not applicable 


\begin{tabular}{|c|c|c|c|c|c|c|c|c|c|c|}
\hline Figure & \#plot & $\mathrm{K}_{4-0}$ & $\mathrm{~K}_{4-1}$ & $\mathrm{~K}_{5-1}$ & $\mathrm{~K}_{3}$ & $\ell$ in eq. $4-0$ & $\mathrm{~K}_{6}$ & {$[\mathrm{E}]_{\text {init }}(\mathrm{M})$} & $\mathrm{K}_{1-1}$ & $\mathrm{~K}_{1-2}$ \\
\hline \multirow{8}{*}{3} & 1 & 1 & \multirow{8}{*}{0} & \multirow{3}{*}{0} & \multirow{8}{*}{0} & \multirow{8}{*}{0} & \multirow{8}{*}{0} & \multirow{8}{*}{$10^{-2}$} & \multirow{8}{*}{2} & \multirow{8}{*}{0.07} \\
\hline & 2 & 0.3 & & & & & & & & \\
\hline & 3 & 0.05 & & & & & & & & \\
\hline & 4 & 0 & & \multirow{4}{*}{10} & & & & & & \\
\hline & $(1+4)$ & 1 & & & & & & & & \\
\hline & $(2+4)$ & 0.3 & & & & & & & & \\
\hline & $(3+4)$ & 0.05 & & & & & & & & \\
\hline & neutral & 0 & & 0 & & & & & & \\
\hline \multirow{6}{*}{4} & 5 & \multirow{6}{*}{$9 \times 10^{-3}$} & \multirow{6}{*}{0} & \multirow{6}{*}{$6.7 \times 10^{-2}$} & 0 & \multirow{6}{*}{0} & & \multirow{6}{*}{$10^{-2}$} & \multirow{6}{*}{2} & \multirow{6}{*}{0.07} \\
\hline & 6 & & & & 1 & & & & & \\
\hline & 7 & & & & 10 & & & & & \\
\hline & 8 & & & & $10^{2}$ & & & & & \\
\hline & 9 & & & & $10^{3}$ & & & & & \\
\hline & 10 & & & & $5 \times 10^{3}$ & & & & & \\
\hline \multirow{5}{*}{5} & 11 & \multirow{5}{*}{8.76} & \multirow{5}{*}{$5.7 \times 10^{-2}$} & \multirow{5}{*}{$5.4 \times 10^{-4}$} & 0 & \multirow{5}{*}{2} & & \multirow{5}{*}{$10^{-1}$} & \multirow{5}{*}{1.9} & \multirow{5}{*}{0} \\
\hline & 12 & & & & 1 & & & & & \\
\hline & 13 & & & & 10 & & & & & \\
\hline & 14 & & & & 100 & & & & & \\
\hline & 15 & & & & 1000 & & & & & \\
\hline
\end{tabular}

Table 3. Fixed values of the parameters for the calculations displayed in figs. 3 to 5 . For all the calculations: $p=q=r=1,\left[M^{\mathrm{m}+}\right]_{\text {init }}=10^{-7} M($ see text). 


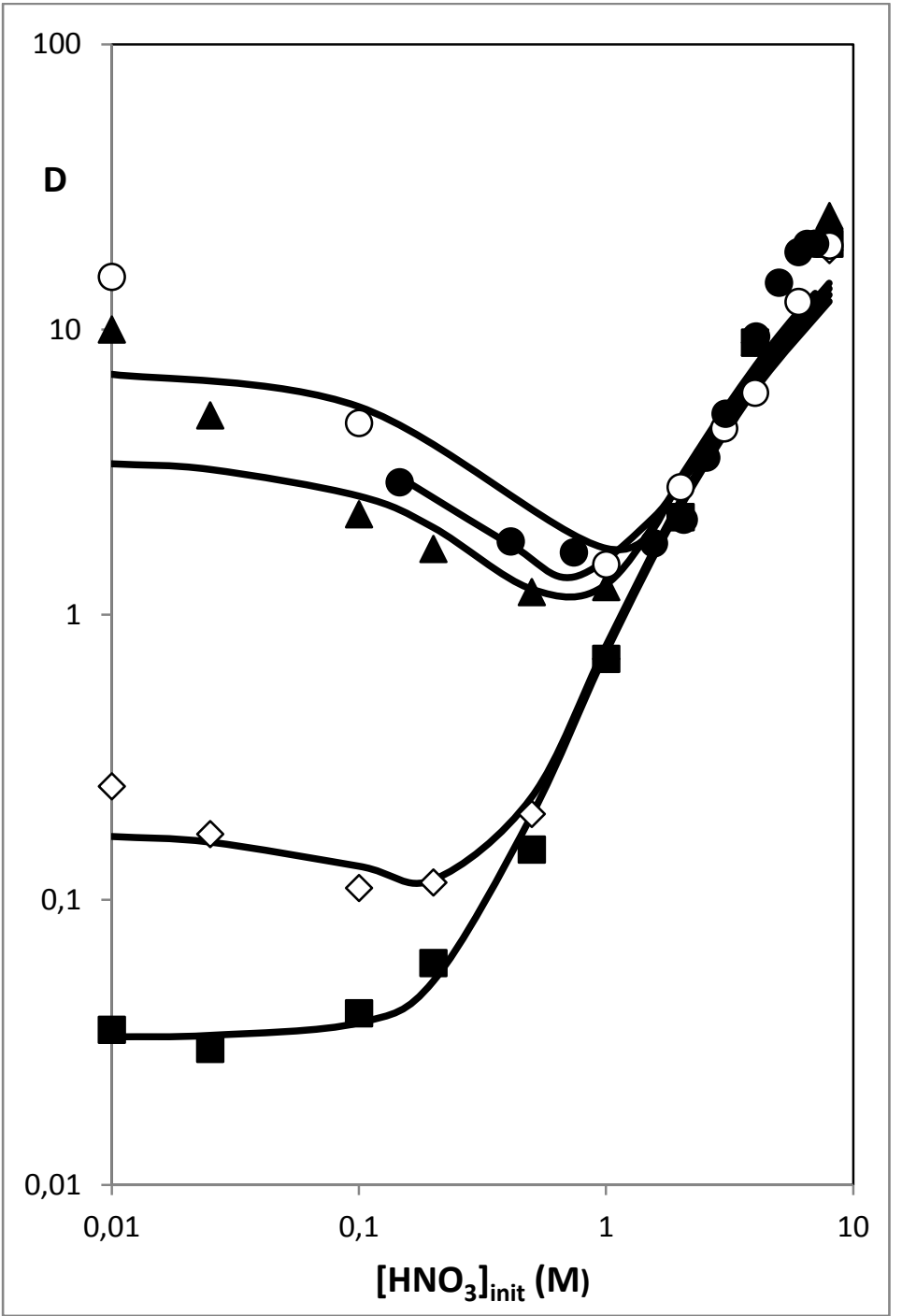

Fig. 1. Experimental data for the reference system $\mathrm{UO}_{2}{ }^{2+} / \mathrm{HNO}_{3} / / \mathrm{TBP} / \mathrm{C}_{1} \mathrm{C}_{\mathrm{n}} \mathrm{imTf}_{2} \mathrm{~N}$. Data redrawn after ${ }^{13}\left(\mathrm{O}: \mathrm{C}_{1} \mathrm{C}_{4} \operatorname{imTf}_{2} \mathrm{~N}\right)$, after ${ }^{10}\left(\bullet: \mathrm{C}_{1} \mathrm{C}_{4} \operatorname{imTf}_{2} \mathrm{~N}\right)$ and ${ }^{12}\left(\boldsymbol{\Delta}: \mathrm{C}_{1} \mathrm{C}_{5} \operatorname{imTf}_{2} \mathrm{~N} ; \diamond:\right.$ $\mathrm{C}_{1} \mathrm{C}_{8} \operatorname{imTf}_{2} \mathrm{~N}$ and $\mathbf{m}: \mathrm{C}_{1} \mathrm{C}_{10} \mathrm{imTf}_{2} \mathrm{~N}$ ). Solid lines: simulations (see text). 


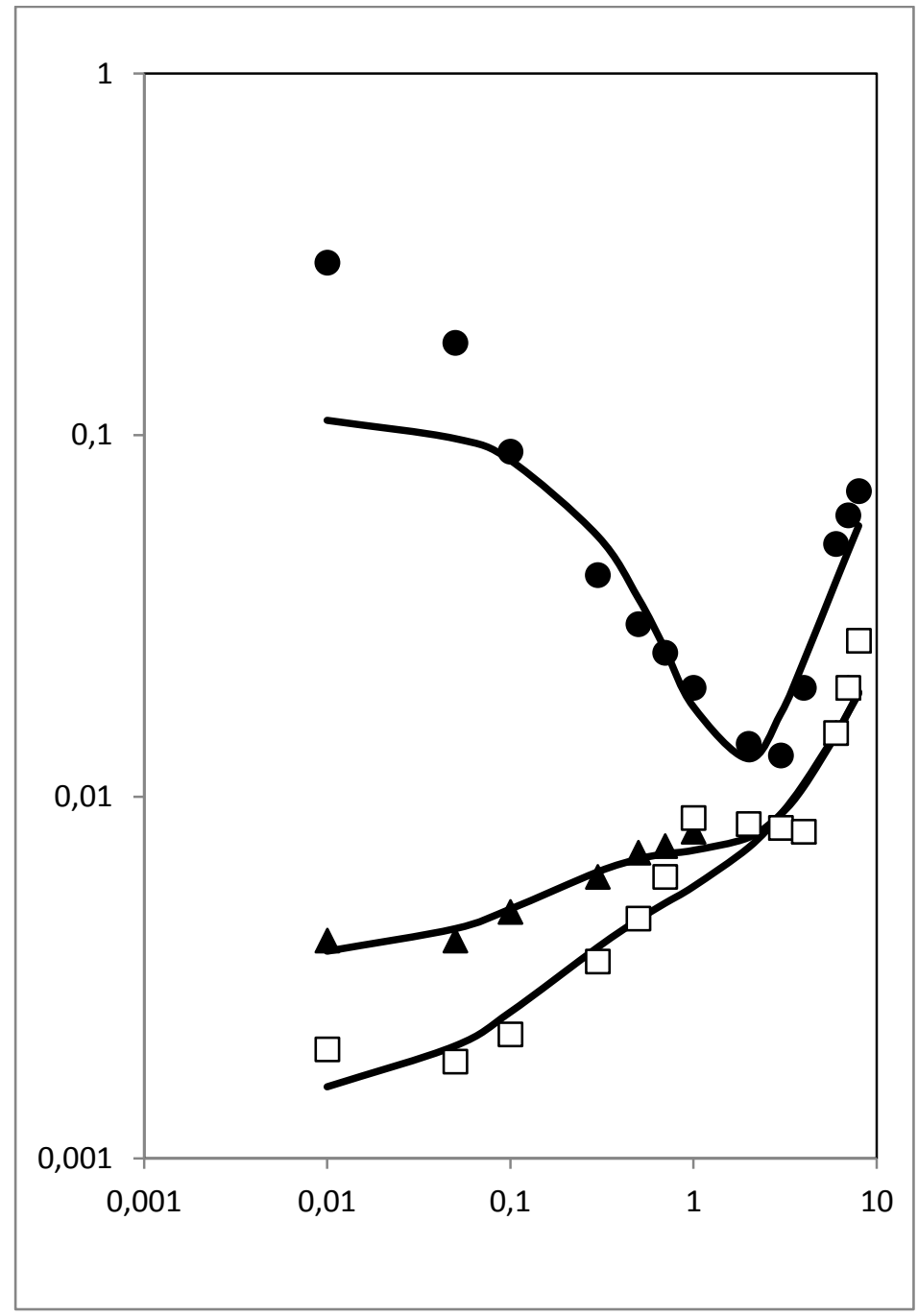

Fig. 2. Experimental data for the reference system $\mathrm{Ca}^{2+} / \mathrm{HNO}_{3} / / \mathrm{DCH} 18 \mathrm{C} 6 / \mathrm{C}_{1} \mathrm{C}_{\mathrm{n}} \mathrm{imTf}_{2} \mathrm{~N}$. Data redrawn after. ${ }^{11} \bullet: \mathrm{C}_{1} \mathrm{C}_{5} \mathrm{imTf}_{2} \mathrm{~N} ; \boldsymbol{\Delta}: \mathrm{C}_{1} \mathrm{C}_{8} \mathrm{imTf}_{2} \mathrm{~N} ; \square: \mathrm{C}_{1} \mathrm{C}_{10} \mathrm{imTf}_{2} \mathrm{~N}$. Solid lines: simulations (see text). 


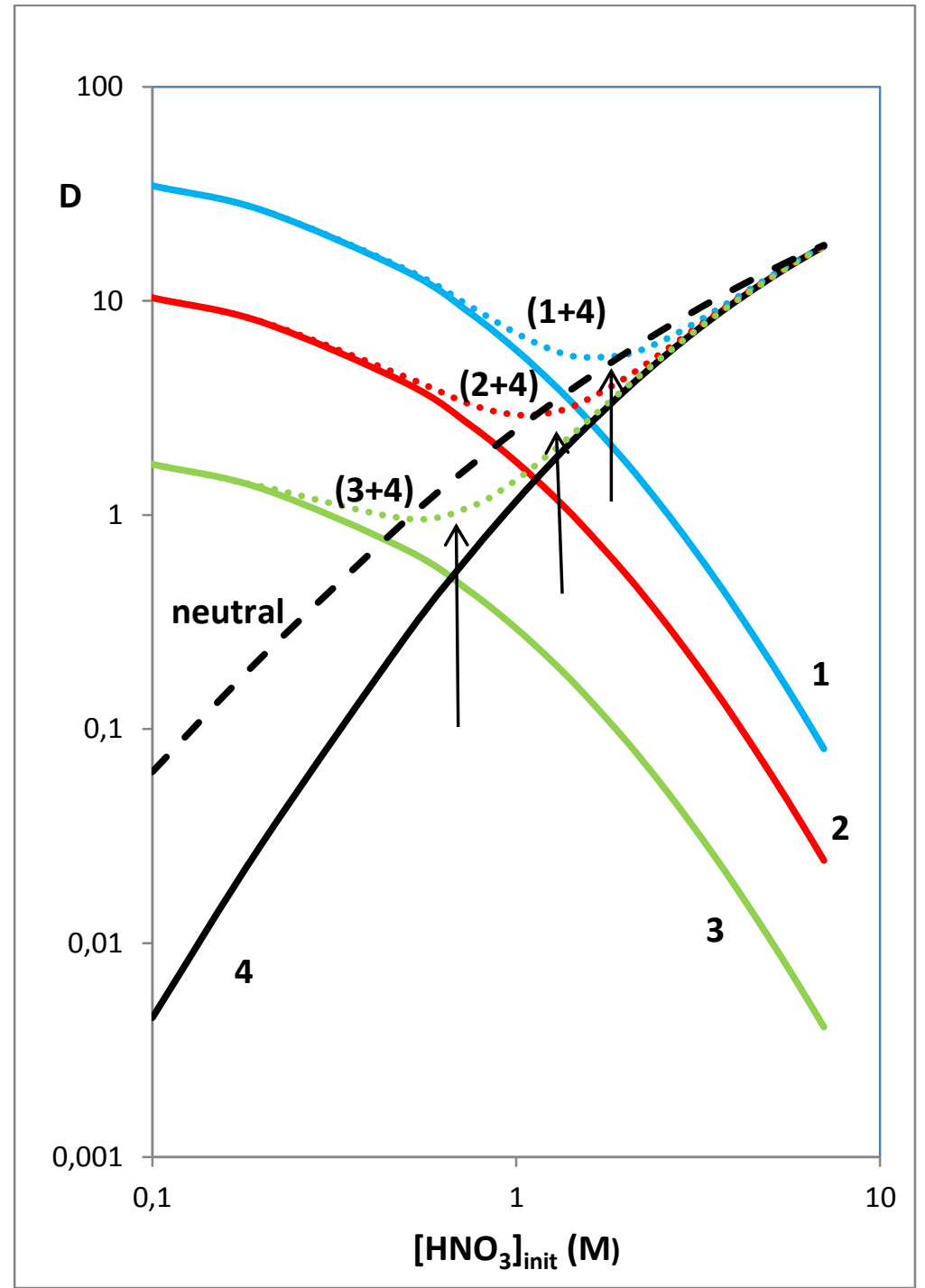

Fig. 3. Calculations of the $\mathrm{D}$ variations according to the values displayed in Table 3 (see text). The numbering refers to the first colomn in Table 3 and the arrows indicate the turnover concentration. 


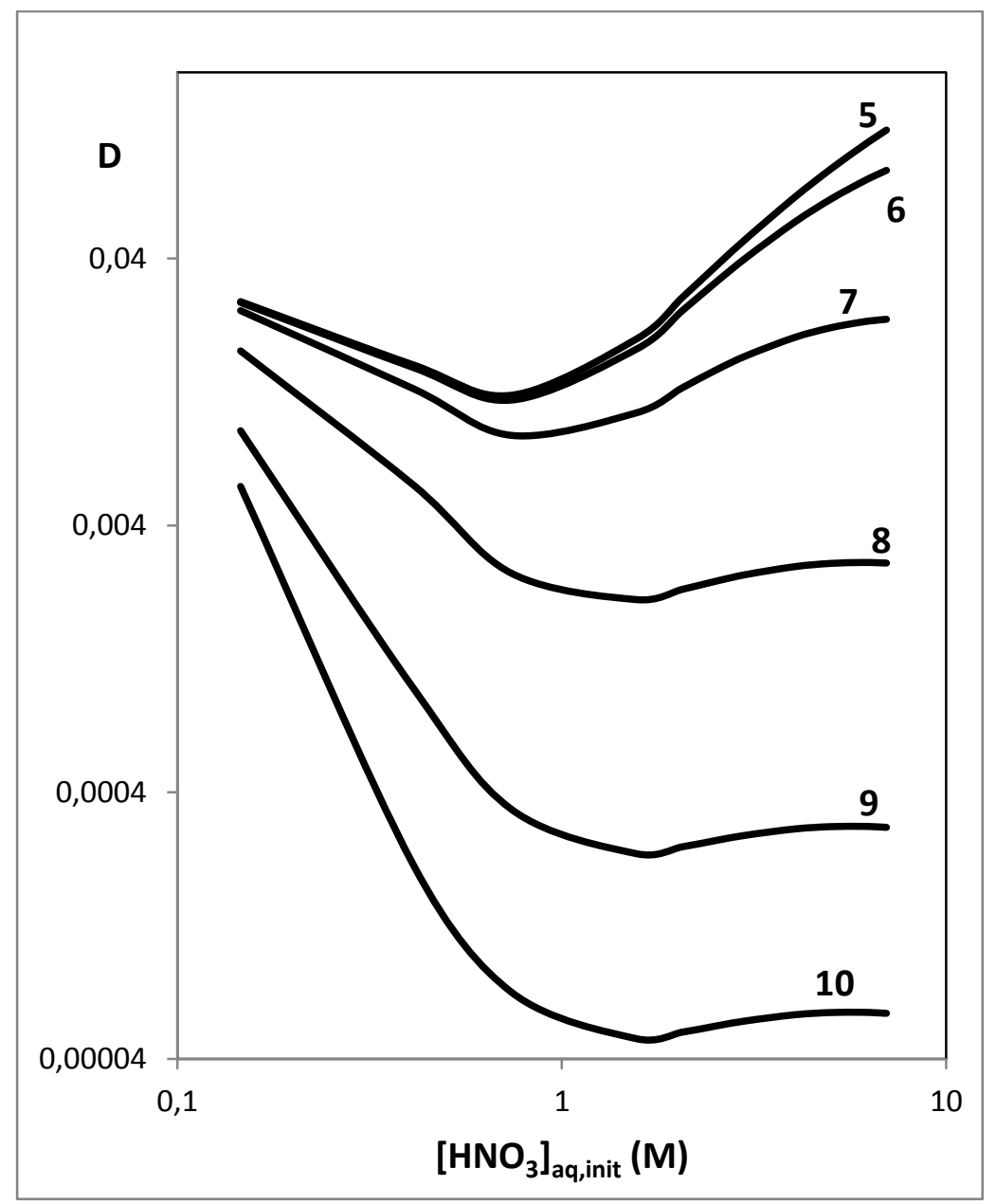

Fig. 4. Calculations of the $\mathrm{D}$ variations according to the values displayed in Table 3 (see text). The numbering refers to the first colomn in Table 3. 


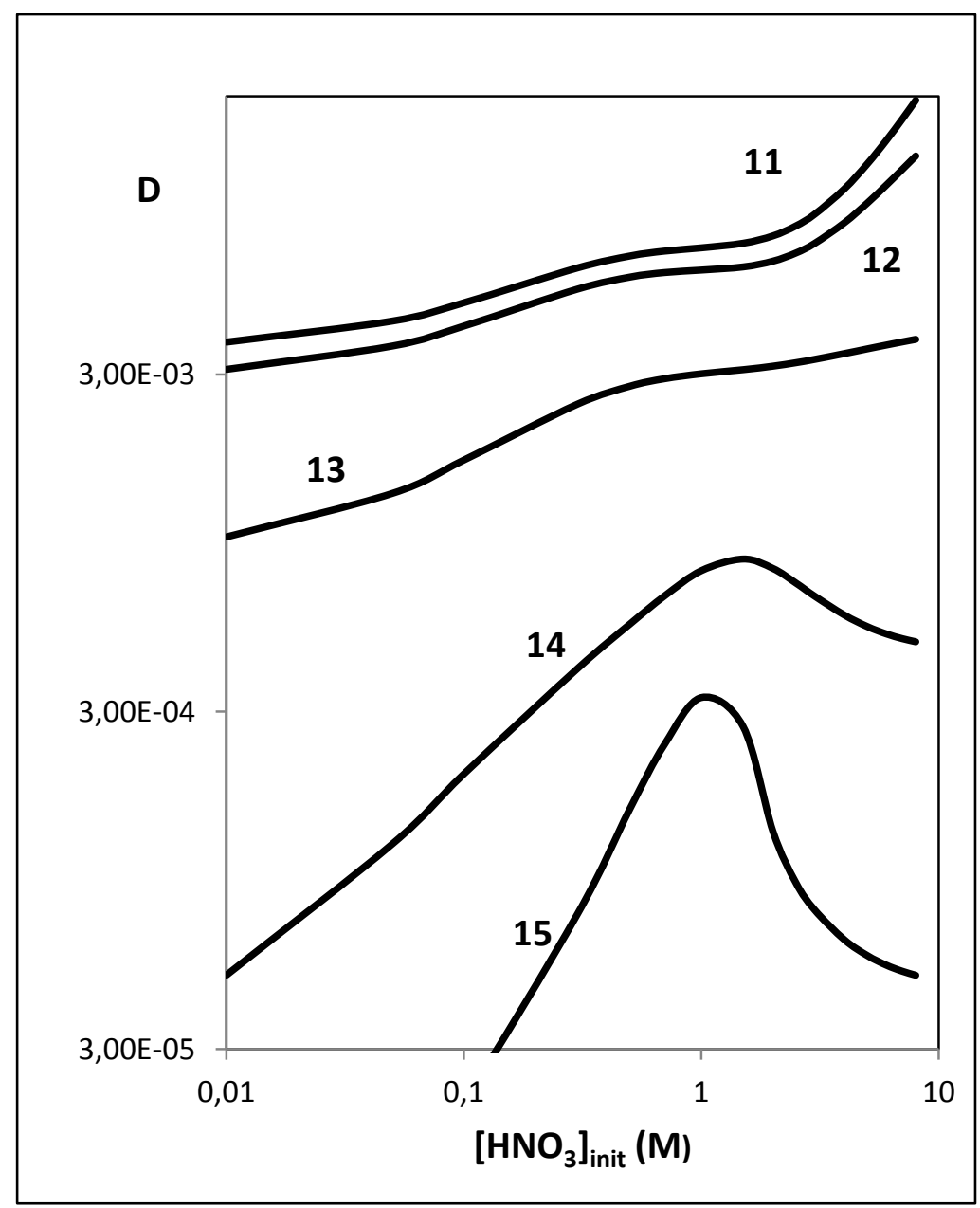

Fig. 5. Calculations of the $\mathrm{D}$ variations according to the values displayed in Table 3 (see text). The numbering refers to the first colomn in Table 3. 


\section{Supplementary materials}

1-butyl-3-imidazolium bis(trifluorosulfonyl)imide $\left(\mathrm{C}_{1} \mathrm{C}_{4} \mathrm{imTf}_{2} \mathrm{~N}\right)$ was purchased from Solvionic (purity: 99.5\%, Verniolle, France) and dried prior to use according to a published procedure. $^{35}$

$0.5 \mathrm{~mL}$ of the IL phase was contacted with $0.5 \mathrm{~mL}$ of an aqueous phase of variable nitric acid concentration. Both phases were contacted in a mechanical shaker at room temperature $(293 \mathrm{~K} \pm 1)$ for three hours followed by 2 min centrifugation. The concentration of $\mathrm{Tf}_{2} \mathrm{~N}^{-}$(see figure below) in the aqueous phase was measured using ${ }^{19} \mathrm{~F}$ NMR (Bruker, $300 \mathrm{MHz}$ ) by mixing an appropriate volume of the sample with $100 \mu \mathrm{L}$ of an internal standard consisting of $50 \mathrm{mM} \mathrm{CF} \mathrm{CF}_{3} \mathrm{COONa}$ in $\mathrm{D}_{2} \mathrm{O}$. The concentration of $\mathrm{Tf}_{2} \mathrm{~N}^{-}$was obtained from the area ratio of the ${ }^{19} \mathrm{~F}$ NMR signal of $\mathrm{Tf}_{2} \mathrm{~N}^{-}\left(\delta_{\mathrm{F}}=-80 \mathrm{ppm} ; \mathrm{CFCl}_{3}\right)$ to the $-\mathrm{CF}_{3}$ peak of trifluoroacetate $\left(\delta_{\mathrm{F}}=-\right.$ 76.5ppm; $\left.\mathrm{CFCl}_{3}\right) .{ }^{14}$

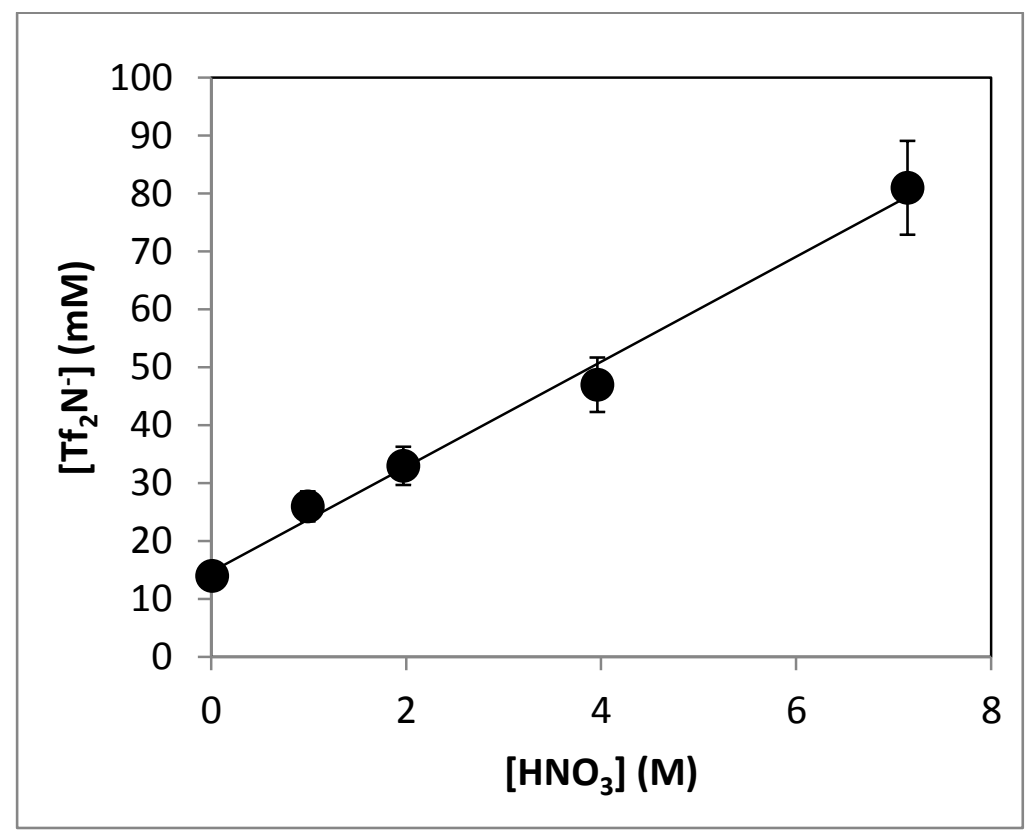

Fig. S1 : Variation of $\left[\mathrm{Tf}_{2} \mathrm{~N}^{-}\right]$as a function of $\left[\mathrm{HNO}_{3}\right]$. Solide line : linear fit.

Linear fit of the data:

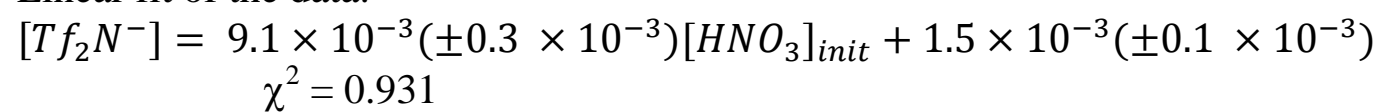

